\title{
Reseña. Silviano Santiago, Las raíces y el laberinto de América Latina. Buenos Aires: Corregidor, 2013.
}

Silviano Santiago es con seguridad uno de los más importantes críticos latinoamericanos de la actualidad. La inserción de su obra en el ámbito chileno ha cobrado fuerza durante los últimos años en virtud de una serie de traducciones, ensayos, entrevistas, encuentros y reconocimientos, donde destacan el volumen comprehensivo Una literatura en los trópicos -elaborado por Mary Luz Estupiñán y Raúl Rodríguez Freire en 2012-, el dossier dedicado a su obra en la revista Papel Máquina en 2013, y una serie de eventos académicos realizados el año pasado en la Universidad de Chile y la Universidad Metropolitana de Ciencias de la Educación. Esta última le otorgó un Doctorado Honoris Causa reconocimiento que ya le había dado también la Universidad Tres de Febrero en Argentina este año. A ello se suma la obtención reciente del Premio Iberoamericano de Letras José Donoso por la Universidad de Talca, galardón que cuenta ya con una serie notable de exponentes y que viene a consagrar su lugar en el campo de la crítica literaria en Chile.

El volumen que nos ocupa fue lanzado en Argentina en 2013 por la editorial Corregidor, con traducción y prólogo de Mónica González García, como parte de la colección Vereda Brasil, un consistente proyecto dedicado a la 
difusión de la crítica y la literatura brasileñas en Hispanoamérica, que ya había publicado sus novelas En libertad y Stella Manhattan. En Las raíces y el laberinto de América Latina, Santiago plantea una relectura comparativa de dos textos fundamentales del pensamiento latinoamericano moderno, inscritos en la tradición del ensayismo de identidad en nuestro continente: Raízes do Brasil (1936) de Sergio Buarque de Holanda, y El laberinto de la soledad (1950), de Octavio Paz.

Articulado en trece breves capítulos, el volumen va de la caracterización de los personajes-tipo elaborados por Paz y Buarque como representativos de la singularidad latinoamericana hasta una lectura anagramática de los núcleos hermenéuticos en los que se fundan ambos ensayos. Reconocido como uno de los introductores de la deconstrucción en la crítica brasileña, Santiago vuelve a valerse aquí de los aportes de Derrida para examinar el particular entre-lugarretomando uno de sus términos clave- en el que se funda la conceptualización de la identidad latinoamericana. Para Santiago, ambos ensayos canónicos marcan, antes que un comienzo, la culminación del privilegio de la cultura letrada, "el fin del saber literario como fundamento primordial de las grandes interpretaciones de América Latina" (29).

Los primeros capítulos están dedicados a una breve contextualización, donde Buarque y Paz aparecen como los primeros en pensar los problemas de la modernización latinoamericana de las primeras décadas del siglo XX -en su forma de dependencia neocolonial, desterritorialización y diáspora. El barón brasileño y el pachuco mexicano comparecen en la lectura, definiendo en sus tensiones el espacio de la singularidad nacional en particular $\mathrm{y}$ latinoamericana en general: "en uno y otro se puede encontrar y analizar la singularidad del latinoamericano en relación al colonialismo europeo y al neocolonialismo norteamericano" (45). Las raíces -que remiten a la historia- y el laberinto -que remite a la poesía-son abordadas como dos máquinas textuales de diferenciación. Si las raíces apuntan a nuestro origen europeo, el laberinto, en el que se inserta el pachuco, se mostrará como un nuevo modo de pensar la 
identidad, un pensamiento de la identidad como enigma, como nudo de contradicciones, como "desafío sin fin" (55) como "una representación posible de la diferencia en sí (différance)" (53). El pachuco se constituye así como "la minúscula contradicción ambulante que aterroriza y fascina -la metáfora justa para un discurso literario que interpreta la singularidad de América Latina en el contexto de un Nuevo Mundo definitivamente americanizado" (63-64). Se desprende luego que, vis-à-vis la hegemonía norteamericana, "Raíces de Brasil es [...] corolario cosmopolita del revisionismo nacionalista originado en el modernismo brasileño y por él difundido. El laberinto de la soledad es, en América Latina, el primer corolario de post-guerra en contexto de la inminente guerra fría" (66).

Los siguientes apartados se dedican a la caracterización del discurso ensayístico de ambos autores, donde se observa primero que allí donde Octavio Paz toma sus recursos y su estructura textual del poema lírico y dramático, el de Sergio Buarque se construye a partir de un personaje/narrador "que parece extraído de la ficción moderna occidental" (75), prolongándose en las figuras del sembrador y el ladrillador, que sirven a Buarque como caracterización de las matrices distintivas y fundacionales del Brasil e Hispanoamérica, respectivamente, para pasar luego a describir los procesos contradictorios en los cuales se asienta el desarrollo global de la cultura brasileña. Esa trayectoria lleva a Santiago a realizar una lectura gramatológica de la organización semántica fundada en la noción de semilla- que, desde la Carta de Pedro Vaz de Caminha hasta su reelaboración y despliegue por Sergio Buarque, funda la configuración discursiva de la singularidad brasileña. El análisis se empeña en mostrar cómo "la escritura controla más la lógica de argumentación presentada por el intérprete [Buarque] de lo que hace creer la simple lectura de las ideas desarrolladas [...] Nuestro interés es visar una relación entre lo que el escritor comanda y no comanda" (110, énfasis suyo). Y va más allá: Santiago enlaza los fundamentos de la estrategia de interpretación del Brasil en Buarque con el conocimiento profundo -no exento de problemáticas- de la tradición literaria lusitana, así como 
su lazo con las obras contemporáneas de Mario y Oswald de Andrade o Joao Cabral de Melo Neto. La sobrancería y el celo, la semilla del sembrador lusobrasileño y el ladrillo del fundador hispanoamericano, todos los tropos y figuras son sometidos a una relectura que sorprende las resonancias inéditas diseminadas en la escritura.

A lo largo de su reflexión, Santiago rescata y reinterpreta los conceptosmetáforas en que los ensayos se articulan, y comienza un recorrido que llevará desde el ascendiente y el contrapunto con la poesía surrealista y constructivista hasta las problemáticas de género que los textos ponen en juego, particularmente en el ensayo de Paz. Santiago se refiere reiteradamente al despliegue de su ensayo como una narrativa, y en esa narrativa destacará el lugar que Paz otorga a las problemáticas de género -siendo el primero en abordarlo, afirma, en el marco de la reflexión atávicamente masculina en torno a la identidad latinoamericana. Paz deviene "el primero de los intérpretes canónicos de América Latina que no esconde la fémina en los subterráneos de la hermenéutica patriarcal colonialista [...] cuestión de género hasta entonces cerrada al ensayismo latinoamericano viril, que comparece de manera abierta en la escritura de El laberinto de la soledad" (148-149, énfasis suyo). El núcleo en juego es el conocido contraste entre los valores del estoicismo y la cerrazón masculinas y la "rajadura" femenina, emblematizada por la Malinche.

Y sin embargo, una lectura deconstructiva de la oposición revelará en un segundo momento que la rajadura femenina describiría "la profundidad de la identidad latinoamericana postcolonial, de la una mujer/hombre rajada, hueca, figura abyecta por excelencia” (158). Más aun, esa lectura abre también la posibilidad de un recorrido, por así decir, a contrapelo de la escritura de Paz, una lectura que sobrepasa la superficie del texto, que se adentra en su inconsciente, y permite indagar en el lugar de la homosexualidad y de la femineidad -y la serie de oposiciones binarias de ellas derivadas- como fundantes de "la imagen mexicana masculina que Paz nos presenta en el choque entre lo cerrado y lo abierto, lo activo y lo pasivo" (164). La metáfora de la herida, la rajadura, la chingada, en su 
relación también con la tradición católica, remitirían al "lamentable estado de la cuestión identitaria en las Américas del sur" (170). El conjunto de la cadena significante en que esas nociones y valores se insertan, se desplazan y significan, servirá a Santiago como guía en el análisis de los discursos subyacentes en $E l$ laberinto de la soledad.

Santiago distinguirá a continuación tres momentos diferenciados, en interrelación, que abastecen la escritura de Paz: el etnógrafo, el ensayista y el poeta. Puestos en movimiento, el rescate etnográfico de la cultura popular es productivizado con el arsenal del ensayista y los medios clarividentes de la elaboración poética -veremos un proceso análogo en Sergio Buarque de Holanda. La poesía, empujando desde el interior de la escritura ensayística y etnográfica, y distanciándose de la función que la modernización latinoamericana otorgó a sus intelectuales, representará entonces el momento creativo que trasciende las oposiciones entre lo cerrado y lo abierto, la ruptura y la búsqueda; representaría una de las salidas posibles del laberinto de la soledad. Su relectura de Buarque y Paz se da entonces como un despliegue de la elección de la acotada serie de conceptos-metáforas que la escritura inscribe y reescribe constantemente, en un vaivén en que se juega la potencialidad de su significación.

La operatoria que define el trabajo de Santiago y que atraviesa, articulándolo, toda la textura de Las raíces y el laberinto, consiste en explotar los múltiples significados, incluyendo sus paradojas y contradicciones, que se desprenden del análisis de un núcleo determinado de conceptos y giros lingüísticos que caracterizan, a veces a contracorriente, la escritura ensayística de Sergio Buarque de Holanda y Octavio Paz. En ese recorrido, Santiago se vale de una multiplicidad de referencias literarias y culturales a fin de revelar aspectos insospechados de las textualidades en cuestión, poniendo a funcionar una máquina interpretativa -de carácter anagramático, en el decir de Derrida- capaz de capturar los fundamentos hermenéuticos de un discurso, volverlos sobre sí, invertirlos, forzarlos, reforzarlos y remitirlos finalmente a sus múltiples relaciones y resonancias intrínsecas. 
El tema de las máscaras, que encuentra lugar en las reflexiones de ambos ensayistas, da pie luego a Santiago para indagar en la particular mirada de Buarque sobre el proceso de modernización del Estado Novo en el Brasil de las primeras décadas del siglo XX, un proceso frente al cual Buarque se enfrentará con una doble voluntad de despegarse, sí, del pasado nobiliario, pero de rechazar asimismo las lógicas pragmatistas del presente. Ambas posturas se debaten en las tensiones originadas por esa reorganización del aparato Estatal de la que Buarque toma distancia -los textos acusan reiteradamente esa tensión. $\mathrm{Y}$ en un segundo momento, Santiago indaga en la figura y el lugar clave -ya no solo para la argumentación de Buarque, sino para el pensamiento brasileño en general- de la cordialidad, mostrando su vínculo íntimo con la máscara y, desde ahí, con la soledad mexicana de Paz.

La narrativa propuesta por Santiago, abastecida por la deconstrucción y la gramatología de Derrida, se alza como un modo ejemplar de hacer crítica, o bien de exceder los lugares comunes de la crítica, para volver a leer el canon latinoamericano desde un -de nuevo- entre-lugar capaz de desentrañar nuevas vetas de significación de la escritura. Santiago ya había declarado que "de las dos obras vecinas y el juego entre ellas, de los dos contextos paralelos y el duelo entre ellos, al autor le gustaría que saliera una compresión renovada de nuestro continente" (27, énfasis nuestro). Sin duda, la nueva constelación de significados que en torno al ensayismo canónico abre su lectura contribuyen a realizar un proyecto ambicioso como el suyo, y que, dicho sea de paso, podíamos imaginar fácilmente prolongado hacia las múltiples regiones del corpus del pensamiento latinoamericano.

Habría que dejar anotado que, desde nuestra perspectiva hispanoamericana, Raízes do Brasil sigue ocupando un lugar marginal, si no ausente, en el canon del ensayo moderno. Es posible y deseable que esta relectura en contrapunto contribuya a establecer una perspectiva nueva, capaz de abarcar comprehensivamente los procesos hispanoamericanos y brasileños, en sus analogías y diferencias. La antología de Sergio Buarque de Holanda publicada por 
el Fondo de Cultura Económica en 2007, que destaca los alcances de su figura, se ofrece como un punto de partida para la ponderación local de su legado y su inscripción en la tradición del pensamiento latinoamericano vista desde este lado del continente.

En paralelo, la relectura de Santiago, que se proyecta desde sus primeros trabajos en un juego constante de reelaboración, nos abre la posibilidad de volver sobre los textos para explorar con una nueva mirada lo que nos han dicho en su pasado y lo que pueden aun decirnos en nuestro presente 